\title{
Mental Health of Children and Young People During COVID-19: A Call for a Preventive Approach
}

\author{
Carl Hermann Dino Steinmetz \\ Expats \& Immigrants B.V., Amsterdam, the Netherlands \\ Email address: \\ carl@expats-immigrants.com

\section{To cite this article:} \\ Carl Hermann Dino Steinmetz. Mental Health of Children and Young People During COVID-19: A Call for a Preventive Approach. \\ Humanities and Social Sciences. Vol. 9, No. 4, 2021, pp. 106-121. doi: 10.11648/j.hss.20210904.15
}

Received: July 16, 2021; Accepted: July 27, 2021; Published: August 5, 2021

\begin{abstract}
This article answers the research question of whether it is true that the socioemotional and psychological wellbeing of children and young people has been worsened by the COVID-19 pandemic. The conclusion is twofold. Doomsayers have written off children and young people because they are socioemotional and psychologically 'damaged' by COVID-19. The positivists, on the other hand, see COVID-19 as a wonderful learning factory where children and young people learn to cope with socioemotional and psychological setbacks. Doomsayers are guided by capitalist insights. Those insights are that children and young people as future "wage slaves" are unable to provide pensions and care for the "older" generation because they have become socially and mentally handicapped by the COVID-19 pandemic. The positivists, on the other hand, are guided by the view that COVID-19 is an incentive to strengthen existing social groups, such as extended families, neighborhoods and tribes, with their solution-oriented approaches to issues and problems learned during COVID-19. This article reaches this conclusion by reasoning critically about the assumptions underlying the view that children and young people are worse off socioemotional and psychologically because of the COVID-19 pandemic than they were before it. Not only does this article make use of logical reasoning, but also of the existing literature on children and young people, the COVID-19 pandemic and socioemotional and psychological wellbeing. This article is structured as follows. Figures are presented on the impact of COVID-19 on children and young people in many countries, non-Western and Western. Furthermore, a distinction is made throughout the article between immigrants, refugees and the indigenous population. The first two groups are particularly affected by COVID-19 in socio-economic and psychological terms, as is the case for the indigenous population with a low socio-economic status. This article also contains the scarce figures on the availability of online education for children and young people, for immigrants, refugees and natives. Finally, the socioemotional and psychological well-being of children and young people is examined through the lenses of negative and positive psychology. This article harshly doubts the efforts of mental health services for children and adolescents, they are too individualistic, especially in the western world. This article supports the preventive approach to the possible psychological lack of socioemotional and psychological well-being of children and adolescents through psycho-education and an approach through extended families by leaning on their sources of strength and resilience. A great example is the Chinese approach.
\end{abstract}

Keywords: Children, Youngsters, COVID-19, Preventive Mental Health, Negative and Positive Psychology, Western, and Non-western

\section{Introduction}

Loud and clear are the cries of alarm about the socioemotional and mental health of children and young people by COVID-19. It is even expected that these COVID19 children and youths are a lost generation. These are pretty bold statements. The cries of doom for children and youth are heard from the field of education, employers, mental health agencies, local and state governments, and certainly from the media. As if children and youth can just be written off. A quote from the Standard (a Belgian newspaper):

"Not only parents, but also teachers have often had to watch with sadness as pupils have lost their courage over the past year. One teacher testified about three suicide attempts in one class. I often felt powerless and 
incompetent. I am not trained for this $\left[4^{1}\right] . "$

For a society steeped in profit-making and making money out of people, COVID-19 and its effects on children and young people is a nightmare. Why, as a reader, you may ask? A nightmare because the current economic model suddenly lacks the foundation of a next generation that must provide for the income and care of the elderly. When children and young people are written off by socioemotional and mental health problems, they are no longer the bearers of the economic system. Apart from the foregoing argument, I assume that mankind is primarily guided by negative psychology, the psychology that constantly inflicts stress, complaints and disorders on us. This article explores what is true of the cry of 'murder and mayhem' when it comes to children and young people and their experiences of COVID-19 in its full breadth.

COVID $-19^{2}$ has ensured that by the 30th of July 2021, a total of 195,911,151 people have been infected, 4,186,739 people have died and 3,961.402.846 vaccinations have been administered, vaccinations mainly in western countries. Earlier research has shown that the above data are an underestimation of the reality [18]. Research suggests that the number of people who have been infected and who have died may need to be increased by a factor between 4-8 [16]. How this relates to vaccinations is unknown. What is certain is that the number of vaccinations are also underestimated, certainly by fake vaccines. A post analysis ${ }^{3}$ shows the following about vaccination and infection of states and counties in the United States, see the attached picture.

\section{Coronavirus infections dropping where people are vaccinated, rising where they are not, Post analysis finds}

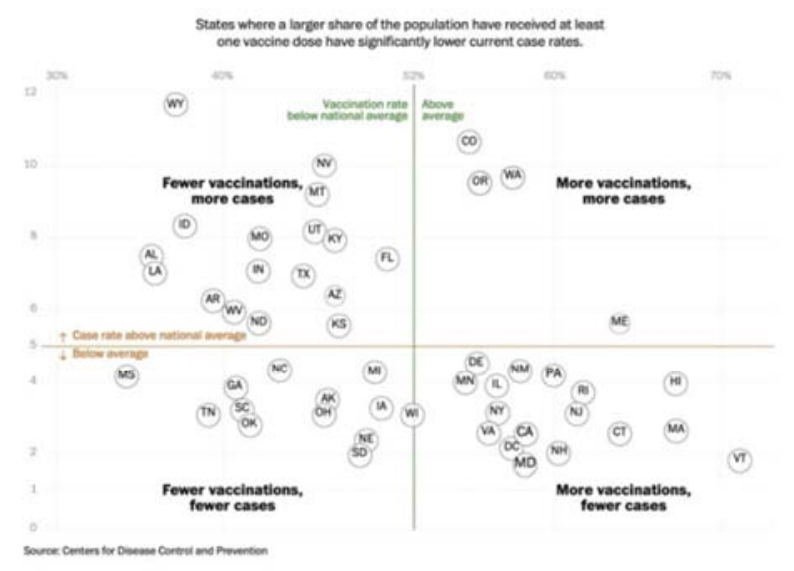

Figure 1. COVID-19 and Vaccination by states and counties in the US.

\footnotetext{
1 https://ap.lc/QPnIk

2 https://www.rivm.nl/en/novel-coronavirus-covid-19/global-spread

3 In a scientific study, post hoc analysis (from Latin post hoc, "after this") consists of statistical analyses that were specified after the data were seen. This typically creates a multiple testing problem because each potential analysis is effectively a statistical test. See https://en.wikipedia.org/wiki/Post_hoc_analysis 4https://www.washingtonpost.com/health/2021/06/14/covid-cases-vaccination-rates/
}

States and counties in the US (17 total) in the 'More vaccinations, fewer infections' quadrant are in the best position. The worst are the states and counties (total 16) within the quadrant 'Fewer vaccinations, more infections'.

It is not yet clear what the above data mean for children and young people. At the inception of COVID-19 in Wuhan China, December 2019, and for the period thereafter, the medical scientific community was of the opinion that young people are virtually unaffected by COVID-19. That view has since been overturned. John Hopkins Medicine ${ }^{5}$ in the United States, Headquartered in Baltimore, Maryland, says the following on its website about young people:

"But according to the U.S. Centers for Disease Control and Prevention (CDC), over the summer, in the United States, people under age 30 accounted for more than $20 \%$ of COVID-19 cases (as of mid-2020, about 26 percent of the world's population were under 15 years old ${ }^{6}$ ) and were seen as more likely to transmit the virus than others. This trend has continued into the fall. Can young people get coronavirus? Yes. Though they are less likely to be hospitalized because of COVID-19 or to die from it, people in their 20s, 30s and 40s can catch the virus, and some develop severe and lasting symptoms, particularly if they are living with obesity, diabetes or high blood pressure (hypertension)."

Another source is the $\operatorname{OECD}^{7}$ (19 October 2020). The OECD said:

"Due to a range of vulnerabilities such as higher incidence of poverty, overcrowded housing conditions, and high concentration in jobs where physical distancing is difficult, immigrants and their children are at a much higher risk of COVID-19 infection than the native-born. Studies in a number of OECD countries found an infection risk that is at least twice as high as that of the native-born. Both the experience from previous economic crises and first indications on labor market and social outcomes during the current pandemic suggest that the COVID-19 crisis is likely to have a disproportionate impact on immigrants and their children."

Recent research calls attention to long COVID-19 in children [21]:

"almost half of children who contract covid-19 may have lasting long COVID-19 symptoms. Symptoms of "long covid" were first thought to include fatigue, muscle and joint pain, headache, insomnia, respiratory problems and heart palpitations. Now, support groups and researchers say there may be up to 100 other symptoms, including gastrointestinal problems, nausea, dizziness, seizures, hallucinations and testicular pain."

The Lancet states that: "Globally, from March 1, 2020, to April 30, 2021, we estimate 1134000 children (95\% credible interval $884000-1 \quad 185000$ ) experienced the death of primary caregivers, including at least one parent

5https://www.hopkinsmedicine.org/health/conditions-and-

diseases/coronavirus/coronavirus-and-covid-19-younger-adults-are-at-risk-too $6 \mathrm{https}$ ://www.statista.com/statistics/265759/world-population-by-age-and-region/ 7https://www.oecd.org/coronavirus/policy-responses/what-is-the-impact-of-thecovid-19-pandemic-on-immigrants-and-their-children-e 7cbb7de/ 
or custodial grandparent. 1562000 children (1 299 000-1 683000 ) experienced the death of at least one primary or secondary caregiver. Countries in our study set with primary caregiver death rates of at least one per 1000 children included Peru (10.2 per 1000 children), South

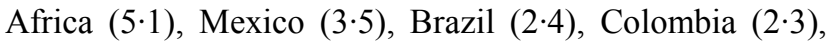
Iran (1·7), the USA (1·5), Argentina (1·1), and Russia (1·0). Numbers of children orphaned exceeded numbers of deaths among those aged 15-50 years. Between two and five times more children had deceased fathers than deceased mothers [5]."

\section{Children and COVID-19: Narratives (Source UNICEF) $^{8}$}

"The COVID-19 pandemic has upended the lives of children and their families across the globe. UNICEF is working with experts to promote facts over fear, bringing reliable guidance to parents, caregivers and educators, and partnering with front-line responders to ensure they have the information and resources they need to keep children healthy and learning."

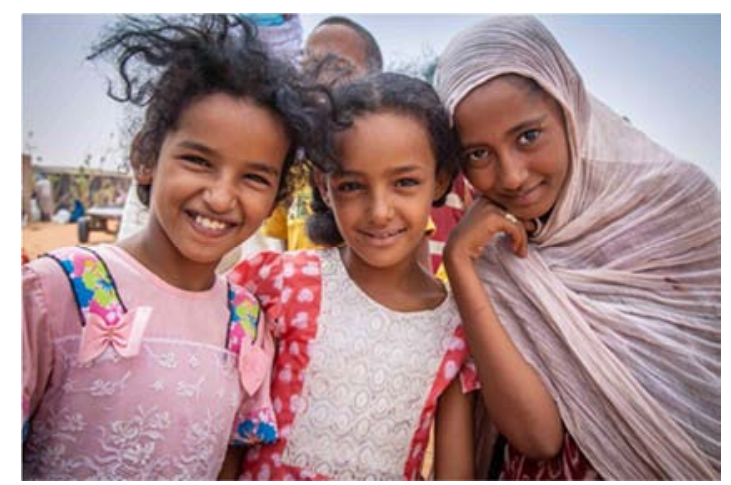

Figure 2. Girls in Danger.

"Where are the girls?" It's a question that is asked too much when stepping into classrooms around the world. And the further up the school years we go, the more the question bounces around an echo chamber.

Massive strides have been made in girls' education. Between 1995 and 2018, 180 million more girls enrolled in primary and secondary school globally. However, a learning crisis persists - and COVID-19's impact risks reversing these gains. While the global learning crisis highlights deficient quality in education systems around the world, it goes much deeper for girls. Girls face multiple vulnerabilities that inhibit their ability to access a basic education: risk of child marriage, early pregnancy, gender-based violence, female genital mutilation, sexual exploitation and child labor.

All these barriers are heightened during crises. Indeed, previous emergencies suggest that girls are at elevated risk of dropping out of school. For example, teenage pregnancies increased during the Ebola crisis, with a high percentage of adolescent girls undergoing first-time pregnancy during the outbreak.

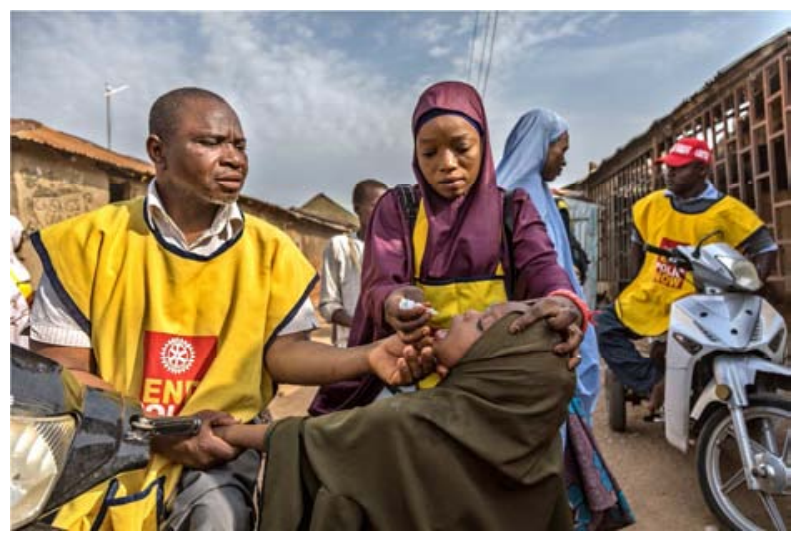

Figure 3. Lack of COVID-19 Vaccines.

"As we seek to ensure that everyone receives a coronavirus immunization, we are also mindful that, as more doses of COVID-19 vaccines become available and delivery is scaled up, the capacity of existing childhood immunization programs will be stretched.

"We must adequately plan for the implementation of COVID-19 vaccine delivery needs in parallel with other immunizations and other essential services, not at their cost," said Henrietta Fore, UNICEF Executive Director."

\section{COVID-19 as a Magnifying Glass for Existing Social and Economic 'Evils}

The COVID-19 pandemic with a possible start date in December 2019 has further exacerbated existing problems of social, health and economic inequality in Europe, the United States of America, New Zealand and Australia. Whether this is the case in Africa, China and India is anyone's guess. The news reports are gloomy on India and Africa, not on China. This is addressed below using OECD research in 2020.

The COVID-19 pandemic acts as a magnifying glass for existing shortcomings in the handling of citizens and their children from Western and non-Western countries, especially those with low socio-economic status (SES). immigrants and refugees, by government agencies, commercial companies and the corporate sector. The disadvantages are economic (exploitation by companies and governments of immigrants, illegal and seasonal workers), disadvantages in education (mainly, lower SES, immigrants, and refugees), climate (poor health in large cities and metropolises, heavy rain and flooding, high temperatures, fires and tornadoes), health care (not or hardly insured, mainly the seasonal and illegal workers) and the housing market (absent, cramped, shabby and dirty housing for immigrants, seasonal workers, refugees and illegal immigrants) and finally governments and businesses that use (black) institutional racism as a business model. Below is an OECD overview of the changes in employment rate corrected for where an immigrant was born [10]. 


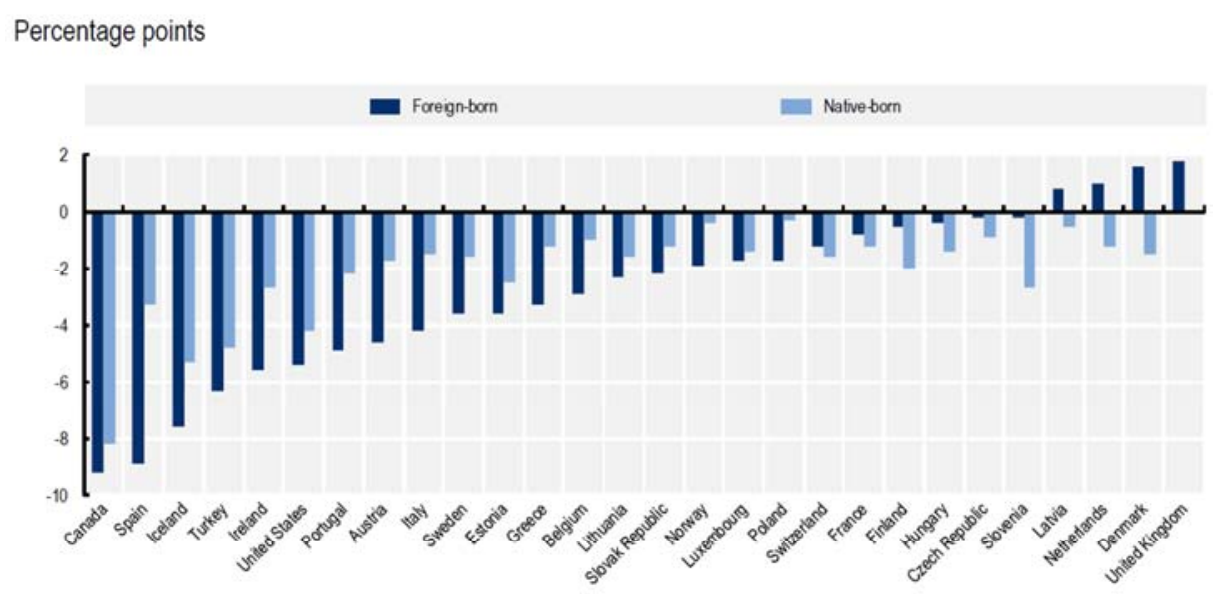

Source: European Union Labour Force Survey (EU-LFS, Eurostat), US Current Population Survey.

Figure 4. Change in the employment rate between Q2 2019 and Q2 2020, by place of birth.

COVID-19 created a new large group of victims among immigrants, refugees, seasonal and illegal workers [18]. Specific consequences for these new COVID-19 victims are: a) the loss of jobs, pushing many families further into poverty, b) the closure of schools, which further increases the existing inequality of opportunity in education, and c) the lack of a "watchdog function" exercised by teachers to be able to spot violence in the family and girls being married off in time. In addition, immigrants and refugees are harder hit by COVID19 than the indigenous population: many immigrants and refugees become infected and die. All this may affect the life expectancy, well-being and physical and mental health of children.

The OECD applies exposure and resilience as key concepts [14] to more accurately understand the impact of COVID-19. Through these concepts it also becomes clear what tools there are to reduce the negative impact. By depicting exposure and resilience, the OECD outlines the conditions in Asia, Latin America and Africa resulting from COVID-19. The OECD applies the following principles: a) the economic state of a country or continent before COVID-19, b) what can be said about the health of the population, the resilience of the health care system, and in particular the percentage of existing underlying diseases among the population, such as obesity and diabetes, c) the demographic composition of the population (after all, in the run-up to COVID-19, the youth were less vulnerable than the elderly) and d) the previous experience of the country or continent with pandemics such as SARS, MERS, EBOLA, etc.

"The ASEAN region boasts strong pre-pandemic growth and moderate debt levels - key factors of economic resilience. Overall, the region's health systems have limited capacities. As social protection coverage is also limited, sizeable informal sectors are likely to be at risk should the pandemic's economic impacts persist over a long period."

"Latin America has stronger resilience scores in terms of social protection, medical capacity and general government performance. While Latin American and Caribbean health systems seem more advanced than in other developing regions, they are struggling with the load of the pandemic. Mounting debt and moderate growth before the pandemic suggest that, in terms of economic resilience, the region will struggle to recover quickly."

"Africa has low scores on resilience. Given lower GDP than in other regions, fiscal space is limited and debt levels are high; this limits the ability to engage in effective spending on economic life support and recovery. For some, the financial situation is dire: Zambia is the first country to suffer a COVID-19-related default. Readiness for digitalization stands out as a particular deficiency in Africa." Globally, COVID-19 has highlighted the lack of national policies to combat poverty, especially child poverty. The same applies to investing in a multi-dimensional and intersectional approach to combat poverty. As a result, Eurochild and its members are calling for recovery plans that take into account the needs of children, national plans to reduce poverty, and targeted support from the EU, including through the introduction of an EU child guarantee. This topic is elaborated on further in this article.

Even more dangerous is COVID-19 for aid workers, especially those in hospitals and nursing homes for the elderly. They are affected by a multitude of stressful life events, such as becoming exhausted by working long shifts, becoming infected and ill from COVID-19 and activists who call themselves 'virus truth', simply deny that COVID-19 exists and that there is an international conspiracy behind vaccination [19]. This has consequences for the home front. These frontline workers are terrified of bringing COVID-19 home to their children, partner and extended family [19].

\section{COVID-19 as a Pressure Cooker}

The COVID-19 pandemic can act as a pressure cooker for nuclear and extended families and their children. Everything goes into the pressure cooker: a) that which was already there, such as family conflicts, child abuse, family violence and secrets, the history of the extended family (e.g. for immigrants, their 
history of colonization, exploitation and slavery, wars and the history of flight, and (black) institutional racism), b) that which the pandemic brings, such as the real and fictional fears of contagion and death from COVID-19, the loss and contagion of family members and acquaintances, being separated from caregivers, conspiracy theories, the media that write about COVID-19 without much reflection and often fire it at us without context, and the disappearance of social context, school and peers, c) the physical and mental state of each member of the extended family, including children and adolescents, and d) the lack of control over the situation that has arisen, such as not being allowed to participate in the discussion and debate about one's own future.

Why am I using the metaphor pressure cooker here? Because COVID-19 compresses everything from the past, present and future, everything that functions intersectionally, without allowing the 'steam' (such as feelings of helplessness in children with pre-existing anxiety and depressive disorders) to escape. People who experience COVID-19 as a pressure cooker, are 'prisoners of time' [3].

\section{Education \& COVID-19}

The following section attempts to depict precisely the educational disadvantages caused by COVID-19 for children and young people. This is an important preliminary step before delving deeper into possible psychological and socioemotional disadvantages due to COVID-19.

In many Western countries, children attend school at an early age. In the Netherlands, children start attending preschool at the age of two. Children of immigrants, refugees and expats learn Dutch here. Compulsory school attendance differs per country ${ }^{9}$, for $15-19$ year old children it is more than $80 \%$ and for 20-24 year old children less than 55\%. From the end of 2019, the COVID-19 pandemic prevented children and young people from going to school to attend classes and hang out with their peers. This was replaced by online learning at home with sisters and brothers, nieces and nephews in the language of the country of residence at that time. Caregivers and parents were asked to support and coach the children in their schoolwork. To put online learning into practice, a whole package of domestic measures is necessary. Basically these are: a) a computer or I-pad for each of the children at home, b) WIFI in good working order, c) a quiet place in the house to do schoolwork, d) structure and regularity in the house, and e) adults who assist and coach the children with their school work at home and who are fluent in the language of the country of residence.

Before the COVID-19 pandemic, this infrastructure with its associated measures was probably only partially in place, probably mainly among the higher socio-economic status groups. The OECD [11] has this to say about it:

"Although schools are better equipped with digital tools than ever before, access to digital learning opportunities is

\footnotetext{
9 https://www.onderwijsincijfers.nl/kengetallen/internationaal/leerlingen-enstudenten/aantallen-deelname-initieel-onderwijs
}

still not equal: children of immigrants tend to be less equipped to face this new transition. In most OECD countries with significant shares of children of immigrants, students with immigrant parents are less likely than students with native-born parents at the age of 15 to have access to a computer and an internet connection at home. However, in spite of the gaps, in all countries, the overwhelming majority of students with immigrant parents do have access to a computer and to an internet connection."

The question is whether the above statement that schools are better equipped with digital tools than ever before is also true for India, China, Africa and South America.

“In today's India, nearly $30 \%$ of the population is not aptly computer literate, and the majority of her educational institutions are situated in areas with limited or subpar internet services. Moreover, same situation is faced by Chinese parents as they were neither trained nor ready to embrace online learning process. A high degree of technical skill and online capability is more warranted for such challenges to be addressed [9]."

Earlier in this article, it was claimed that COVID-19 has and continues to function as a magnifying glass. Therefore, it is wise to find out how children of immigrants perform at school. The OECD [11] says the following about this:

"On average across the OECD, students with immigrant parents are twice as likely to be in the bottom quarter of the PISA index of economic, social and cultural status. Prior OECD work has shown that students from such disadvantaged backgrounds are less likely to have access to a quiet place to study than their more advantaged peers and to be proficient in using technology for schoolwork already before the pandemic. Indeed, students with immigrant parents are consistently less likely to have access to a quiet place to study, with the exception of foreign-born students in New Zealand, but again the differences are not large and in all OECD countries, at least three out of four children of immigrants report to have access to a quiet place to study at home.

On average across OECD countries in 2018, close to half (48\%) of 15-year-old students with immigrant parents did not speak the language of the PISA assessment at home. This proportion was particularly large in Austria, Finland, Germany, Iceland, Luxembourg and Slovenia.

While the available comparative data on student disadvantage is based on PISA data and thus refers to students at the age of 15 , the negative impact on children of immigrants is likely to be higher for smaller children. Smaller children likely depend more on parental support, and the impact of not having many chances to practice the host-country language during several months may impact particularly at younger ages."

The difference between the children of immigrants and native born is clearly set out in the following figure. The symbols in the figure indicate for almost all countries that children of 'foreign-born and native-born with immigrant parents' have a disadvantageous PISA index for economic, social and cultural status. Almost all of the 'jujubes' are at the top of the figure, while the squares for 'native-born with 
native-born parents' are almost all at the bottom. The latter stands for low disadvantage.

\title{
Percentage of students in the bottom quarter of the PISA index of economic, social and cultural status
}

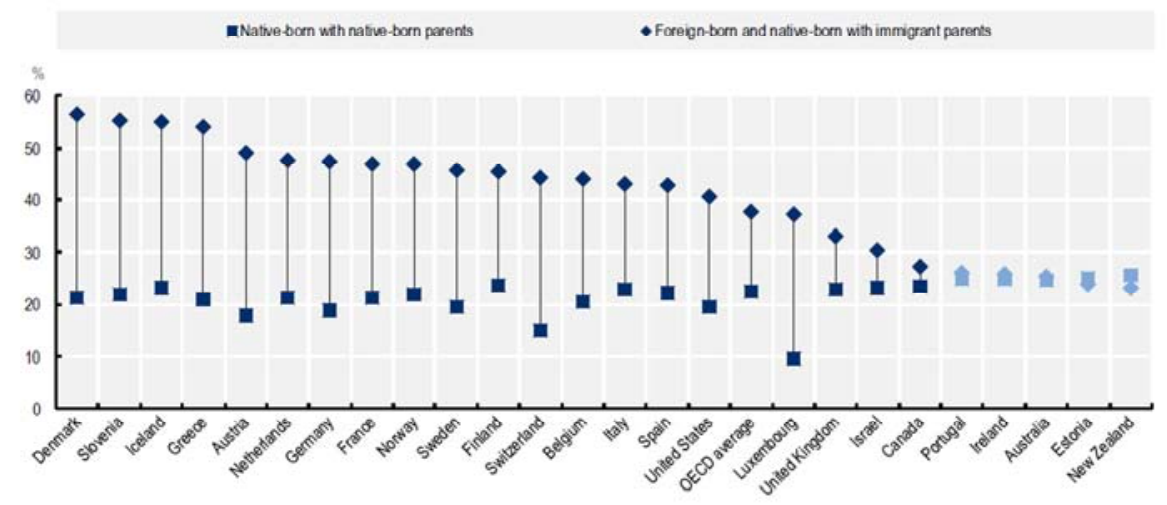

\begin{abstract}
Note: The PISA index of economic, social and cultural status (ESCS) was created using student reports on parental occupation, the highest level of parental education, and an index of home possessions related to family wealth, home educational resources and possessions related to "classical" culture in the family home. Statistically significant differences between the percentages of students with and without immigrant parents are shown in a darker tone. Only countries where the percentage of immigrant students is higher than $5 \%$ are shown. Source: OECD, PISA 2018 Database, adapted from OECD (2020[311).
\end{abstract}

Figure 5. Percentage of disadvantaged students, by immigrant background.

The earlier argument is that COVID-19 only widens the differences between "haves" and "have nots", in short COVID-19 has not done the youth any good. The above outlines the pre-COVID-19 impact on the education of 15year-olds of immigrant origin. How this will develop further for children and young people due to the lack of classroom teaching during COVID-19 is another question that urgently needs an answer. A second question that also addresses the magnification of the difference between 'haves' and 'havesnot' is if the COVID-19 pandemic in education 'damages' children and youth, what is the extent of that. Both questions are attempted to be answered below. The question of the extent of the damage is called hysteresis in science. It represents the long-term effect of closing educational institutions for pupils and students. Fortunately, the Harvard calculation masters have made an attempt to do so [11].

"The OECD-Harvard Graduate School of Education Survey estimated the impact of school closures on education continuity to be at least two months of instruction for half of the primary and secondary school students. During this time, a number distance-learning solutions such as online classrooms and broadcasts, as well as computer-assisted learning were implemented to bridge the gap between schools and learners, but the impact on education outcomes remains uncertain, especially for children of immigrants. In terms of material resources, however, there is little evidence of a disproportionate impact."

The OECD [11] states that the long-term effect of closing educational institutions should not be exaggerated. Evidence is drawn from the 2011 earthquakes in Christchurch, New Zealand, which caused schools to remain closed for long periods. In short, the fact that the negative effects were small at the time was mainly "due to the fact that the teachers focused on "what needs to be taught". The concern is mainly for pupils and students who, for much of the lockdown, could not be reached by their teachers and the municipal officials who tried to contact them. Such prolonged absence could have an impact on the motivation of a pupil or student.

Furthermore, this OECD report makes two striking statements: a) the detrimental effect of closing educational institutions may no longer be visible if the former pupil or student has completed her/his education and b) that the detrimental effects will mainly fall on the shoulders of the children of immigrants.

In Amsterdam, the Netherlands, a summer school will be offered for the second time in the summer of 2021. Furthermore, Amsterdam relies heavily on weekend education to support the children of immigrants and refugees. During COVID-19, Amsterdam continued to provide face-toface education to the most vulnerable children. In this way, Amsterdam tries to prevent more serious disadvantages.

The above discourse on the impact of COVID-19 on pupils and students was not intended to downplay the supposed negative effects. That would be very unjust, also because the data are still far from complete. The OECD [11] will support the world through its PISA survey. They are currently working on a module to better compare countries in terms of the effects of COVID-19 on school attendance. Much of the responsibility for preventing disadvantage is also placed on the governments of countries, especially where the children of immigrants are concerned.

"Second, countries need to prepare strategies to mitigate effectively this risk in case of future lockdowns. This can include among others:

1) To monitor closely student engagement by following up on their attendance, behavior, and learning progress.

2) To address the potential barriers to student engagement by offering adequate resources (such as laptops or tablets, and safe places to learn). 
3) To provide individualized support to students so they can get the best out of the new modes of education delivery."

\section{COVID-19, Children, Youngsters and Psychological Wellbeing}

Section 6.1 is written from the perspective of negative psychology on the development of children and young people during and after COVID-19. This means that it will mainly deal with discomfort, complaints, disorders and symptoms. This section also focuses on a Chinese controlled preventive approach to minimize health problems in children directly or indirectly affected by COVID-19. In section 6.2 , preventive medicine has been looked at from the point of view of negative psychology. Section 6.3, on the other hand, is mainly devoted to the positive psychology view of the effects of COVID-19 on children's psychological well-being. Key concepts are resilience and sources of strength. Positive psychology is mainly looking for ways to despise the effects of COVID-19 on children's well-being. In the 'old' world, this is called secondary and tertiary prevention to prevent the effects from worsening.

\subsection{Negative Psychology and a Chinese Preventive Health Program}

Famous psychological research [2] shows that small children, even babies, and pets, such as dogs, cry when a mother enters a room sad. Ever heard this saying? "When mama ain't happy, ain't nobody happy ${ }^{10}$." That saying can ring true because your baby's feelings are likely to mirror yours. In fact, even babies can distinguish a happy from a sad expression. This is called Theory of Mind and stands for empathy and understanding the other person.

It can be deduced from the above that even babies, but certainly also older children, inherit their mother's worries. If the mother worries about COVID-19, for example, because she works in care, her children will pick up on this through their Theory of Mind. What the situation is with fathers and other caregivers is not known because much experimental psychological research on Theory of Mind has been done in Western laboratories. What we have to do then is speculate and reason. From that perspective, it seems plausible that babies and older children will pick up what their parents are worried about. I myself have often been able to observe this as a grandfather. By simulating, an estimate can be made of the number of people and, by inference, children in the world who come into contact with caregivers.

According to the Global Health Workforce statistics database $^{11}$ the number of estimated health personnel in the world in the period 2013-2019 is:

10 https://www.webmd.com/parenting/baby/features/stress-and-your-baby\#1 11 https:/www.who.int/data/gho/data/themes/topics/health-workforce

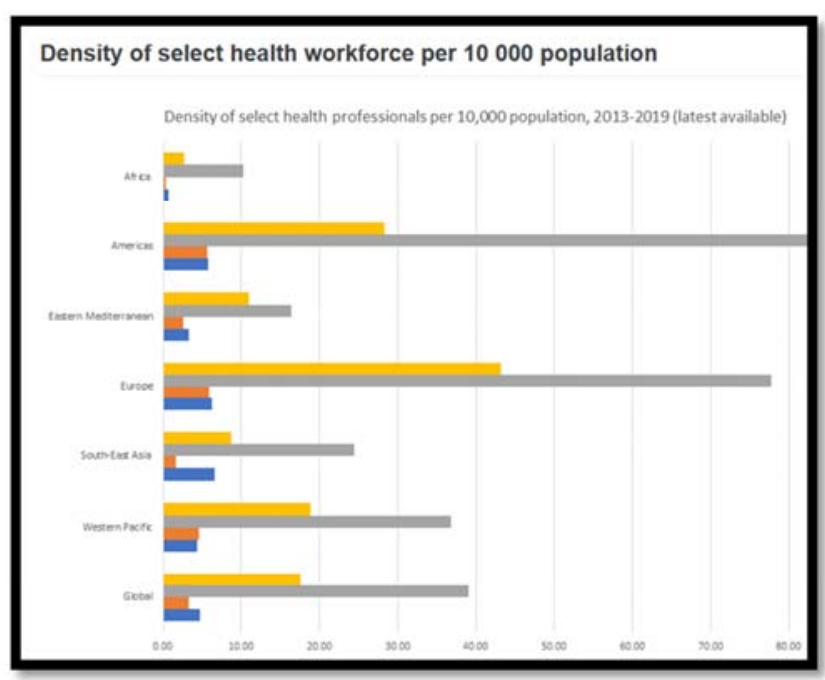

= Medical doctors $=$ Nursing and midw fery personnel $=$ Dentists $=$ Phamacists

Figure 6. Density of select health workforce per 10.000 population.

The total world population in 2021 will be 7.9 billion. In terms of the number of doctors, that is almost 14 million people, nurses and midwives almost 31 million people, and dentists and pharmacists almost 7 million people. Assuming that the extended family including a care worker has about 42 members, the active number of family members worldwide who are exposed to a risky healthcare profession by COVID19 is about 2.2 billion. This is a significant proportion of the world's population. In total, there are 2.2 billion children on earth. In short, about 560,000 children have caregivers in their extended family who work in care.

The fact that many children and young people can sense the often serious concerns of their parents and caregivers should not automatically lead to the conclusion that these children and young people are worse off socioemotional and psychologically. To draw that conclusion is to make a fallacy. To put it simply, that fallacy is that 'bad' experiences lead to new problems. This fallacy arises because people are often not aware of their resilience and sources of strength with which they learn to solve wretched or difficult problems. In scientific jargon, this is called secondary appraisal [20]. In short, the bold proposition in this context is that learning to overcome miserable experiences leads to socioemotional and psychological growth. In the world of psychotrauma, this is called traumatic growth.

From the perspective of 'negative' psychology, attention is now paid to how psychiatry and psychology view the consequences of COVID-19 for children and young people. Below is a Western view of how psychiatry and psychology view COVID-19, children and young people.

"The mental health consequences of the COVID-19 pandemic in youth have been diverse, ranging from the onset of stress-related disorders to the exacerbation of preexisting disorders, including a flare-up in cyber dependence, and also, in rare cases, the alleviation of disorders (e.g., school phobia for some). During the pandemic, a primary role for mental health expertise is 
distinguishing normative responses to pandemic adversities, that are not associated with severe psychological distress or with significant impairment, from pathological responses that require a specialized intervention. Nevertheless, the fear of illness and death and the many stressors of the pandemic can result in symptoms that correspond to adjustment disorders and to posttraumatic stress disorder (PTSD), diagnoses that can be made during ongoing dangers (such as pandemics, wars, domestic violence) [15]."

I have borrowed a quote from the article by Rousseau [15] that clarifies in a nutshell what young people can face as a result of COVID-19. It is about Lucia who is known for her obsessive-compulsive disorder and her desire to commit suicide. On top of that comes COVID-19. Her therapist gives Lucia a tool to regain control by using skype to guide her grandparents through the pandemic.

"Lucia is a 10-year-old girl presenting to the emergency room with an exacerbation of her obsessive-compulsive disorder (OCD) symptoms and suicidal ideation. Her preexisting hand-washing rituals had become pervasive. She reported having the impression that the only way to escape death was to commit suicide by jumping off her apartment building. Surprisingly, she minimized the pandemic, stating "I don't care."

However, her mother reported that Lucia had recently become terrified at the idea that her budgies could be killed by a virus, and added that the cognitive behavioral therapy (CBT) that they were receiving, was not working well in the present context. To increase Lucia's sense of control and agency, the clinician asked Lucia to promote the safety of her grandparents by skyping with them every day and reading them a story. Lucia and her mother stated that they felt better after the assessment."

It has previously been promised that attention will also be paid to the non-Western world and how it views COVID-19, children and their mental well-being.

In the vast country of India, the focus of the impact of COVID-19 on children and adolescents is on crimes, such as child marriage, child labor, family and domestic violence, illtreatment and sexual abuse [8].

"The death, illness or separation of the beloved caregiver, isolation in treatment centers or even quarantine at home can have a negative impact on children's mental health. Loss of parent and caregiver due to disease or isolation of parents can make the child anxious and alone. Also, children separated from parents like those who are in hostels/ coaching institutes in distant cities and countries are prone to abuse and are under tremendous mental stress. Quarantine procedures can create anxiety and panic in the community, especially in children, if they are not able to assess what is happening. In the case of special children or children with a pre-existing mental health condition, there can be worsening of mental health conditions due to lack of support."

China has correctly assessed the severity of the COVID-19 pandemic. This assessment was also based on scientific research. Below is presented the result of a Chinese study two weeks after the outbreak of COVID-19 on the psychological well-being of Chinese children during the COVID-19 pandemic [6].

"The results of this cross-sectional study suggest that nearly $40.4 \%$ the sampled youth were found to be prone to psychological problems and $14.4 \%$ the sampled youth with Post-traumatic stress disorder (PTSD) symptoms. Univariate logistic regression revealed that youth mental health was significantly related to being less educated $(\mathrm{OR}=8.71$, 95\%CI: 1.97-38.43), being the enterprise employee $(\mathrm{OR}=2.36$, 95\% CI: 1.09-5.09), suffering from the PTSD symptom $(\mathrm{OR}=1.05,95 \% \mathrm{CI}: 1.03-1.07)$ and using negative coping styles $(\mathrm{OR}=1.03$, 95\%CI: 1.00 1.07)."

Hong Kong conducted a comprehensive study on 'Vulnerability and resilience in children during the COVID19 pandemic [22].'

"The study included 29,202 individual families; of which 12,163 had children aged 2-5 years and 17,029 had children aged 6-12 years. The risk of child psychosocial problems was higher in children with special educational needs, and/or acute or chronic disease, mothers with mental illness, single-parent families, and low-income families. Delayed bedtime and/or inadequate sleep or exercise duration, extended use of electronic devices were associated with significantly higher parental stress and more psychosocial problems among preschoolers.

In conclusion, this study suggests additional support should be targeted at children in vulnerable groups to reduce the consequences of deepening social, economic, and health inequalities, especially in families with mental and/or physical illness and single-parents families. Measures such as online visitation and consultation, and extra funding support for home learning in underprivileged families should also be considered. Our findings highlight the importance of strengthening family coherence, adequate sleep and exercise, and responsible use of electronic devices to promote family wellbeing during the COVID-19 pandemic. It is important to prioritize resources to those in need and establish strategies to strengthen family care to support our children in this difficult time."

China has introduced strict quarantine measures following the outbreak of COVID-19. This affected more than 80,000 people with COVID-19 and 690,000 people in close contact with those already registered as infected and in quarantine. This included a large number of children [7].

"For children who are quarantined at home with their parents or relatives, the stress caused by such a sharp change in their environment might be eased to some degree. However, children who are separated from their caregivers require special attention, including children infected with or suspected of being infected with severe acute respiratory syndrome coronavirus 2 (SARS-CoV-2), who are quarantined in local hospitals or collective medical observation centers; and children whose 
caregivers are infected with SARS-CoV-2 or who have died from the disease and are thus under the care of social charity groups. These children might be more susceptible to mental health problems because of their higher risk of infection, and the grief and fear caused by parental loss or separation.

The Chinese government has introduced a series of strategies to prevent the possible mental health problems that may arise in children quarantined during the COVID19 pandemic. For example, in many Chinese tier 1 cities -typically the largest and wealthiest-like Shanghai, Guangzhou, and Hangzhou, nurses are guaranteed to be available $24 \mathrm{~h}$ per day in the children's isolation ward. Nutritionists are invited to give professional guidance for children's diets according to their medical conditions and normal developmental requirements. To reduce fear and other psychological discomfort, children who are quarantined can communicate with their parents via mobile devices at any time. Many citizens from the local community or district volunteers act as temporary mothers to care for recovered children after their discharge, when their caregivers are not available because of infection, quarantine, or death. In response to the notice on improving rescue and protection for children without effective guardianship issued by the Ministry of Civil Affairs, many cities like Zhengzhou opened free psychological counselling hotlines, which were available $24 \mathrm{~h}$ per day. Most recently, the National Health Commission of China issued guidelines and listed specific intervention strategies for children who are quarantined in collective medical observation centers. For example, these measures seek to increase children's communication time with their parents; increase children's access to disease information via comic books and videos; guide children to establish a regular activity schedule; provide night lights and small gifts; and provide timely referrals to psychiatrists when children feel mental discomfort, such as worry, anxiety, difficulty sleeping, and loss of appetite."

\subsection{Negative Psychology and a Preventive Health Approach}

Rousseau [15] advocate working with an extended family approach, also known in therapy as a system approach, partly because the extended family has its own genesis and history of existence. After all, the pillars of support for children and young people are their caregivers, also in dysfunctional extended families. Children and young people mirror their caregivers and parents. An extended family approach makes it clear that it can be helpful if a social worker explains to parents and the child that, for example, the child's aggressive behavior is a reaction to the parents' fears and concerns about COVID-19 risks. Rousseau [15] comes with a 'laundry' list of take-home measures for professionals working with children.

Take-Home Messages for Professionals Working in Child Mental Health Units During a Pandemic

1) The mental health consequences of a pandemic on youth are associated with communication around the pandemic, as well as with individual, (extended) family, and community dynamics.

2) The pandemic may trigger anxiety symptoms but also externalizing behaviors (e.g., acting out), and increase suicide risk and substance abuse, in particular among adolescents.

3) Supporting parents and communities by providing guidance can help reduce stress-related symptoms in children and adolescents.

4) Pre-existing mental health disorders in children and adolescents may be exacerbated by the social and family contexts during the pandemic.

5) Assessment of risks of suicide and aggressive behaviors and development of strategies for risk reduction and safety planning in the context of state and national stayat-home policies are important components in the role of child and adolescent psychiatrists and other mental health professionals in providing care to individual children and adolescents during this crisis.

6) The pandemic has led to an expanded role for telepsychiatry in current efforts to reduce safety risks associated with COVID-19 exposure for patients of all ages and healthcare workers.

7) The disruption of standard services and health professionals' security concerns call for a systemic and resilience-oriented approach that relies largely on family and community resources.

8) The elevated stress is likely to cause tensions within institutions and teams. Acknowledging and validating clinicians' legitimate fears and mobilizing courage and hope among them is essential.

It is noteworthy that psychoeducation is missing from the above list of Rousseau [15]. For very young children, this can be done with picture and story books. That has just been developed by the Inter-Agency Standing Committee Reference Group on Mental Health and Psychosocial Support in Emergency Settings (IASC MHPSS RG). This picture and read-aloud book is called "My Hero is You", a fictional book developed by and for children aims to help families understand and cope with COVID-19, and is available in the languages of 104 countries (CIASC, 2020) ${ }^{12}$.

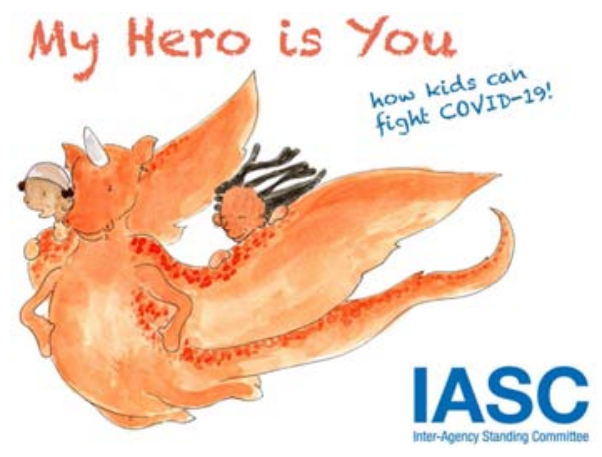

Figure 7. My Hero is You.

12 https://www.unicef.org/coronavirus/my-hero-you 
The report "Growing up in lockdown: Europe's children in the age of COVID-19. 2020 Eurochild Report. \#PuttingChildrenFirst" puts forward a number of policy recommendations for European children during and after COVID-19. Key recommendations for youth mental health care are:

1. Investigate and evaluate measures for children in vulnerable circumstances with the aim of 'quickly identifying those of them who are in acute need of help'.

2. Research and evaluate how the youth mental health services deal with the corona crisis and the corona measures. Make sure that children play a prominent role in this.

3. Make sure that children and young people get a prominent role in youth care and youth mental health care and that they participate in the changes (read recovery plan) concerning corona.

Making young people an active part of the anti-COVID-19 approach

The living and economic context of children and young people has been battered by COVID-19. COVID-19 particularly victimizes caregivers and parents with low socioeconomic status (SES), immigrants and refugees, the latter two categories partly overlapping with low SES. The reasons are manifold. First, these people-victims of COVID-19 live in small houses with many people. Second, the parents and caregivers work in places where government measures are not observed, such as washing hands and keeping a distance. Third, these people-victims of COVID-19 have poor or no internet and no or not enough computers for their children, which further delays their education. Fourth, these peoplevictims are at high risk of multiple victimization, including domestic and family violence, and institutional racism, discrimination and exclusion at school, in care, at work, on public transport and on the street.

The short-, medium- and long-term consequences of the effects of COVID-19 on children and youngsters are not yet known. My assumption is that this might cause these children and young people to stagnate in their IQ, EQ, SQ, ICT-Q and Culture-Q. It is known that these cognitive, social and emotional abilities and potentials continue to develop during the course of children's and adolescents' lives. But that is not all, children and young people learn a great deal from their peers. Examples include responding to and understanding social developments and new trends, dealing with other people, dealing with teachers and other adults, presenting oneself, taking initiative and persevering. If this learning process stagnates, young people can become lonely, depressed and even consider ending their lives. The purpose of life eludes them because of COVID-19 isolation measures, such as keeping one's distance, not going out with peers and especially sitting at home a lot.

Euphemistically, it is also claimed that inequality of opportunity - especially for our youth - has been increased by COVID-19. I do not like this concealing term 'inequality of opportunity'. What has in fact taken place is a violation of human and child/ youth rights by governments. As an activist, I am surprised that "the rights of children and young people cannot be claimed by them" or, in other words, that adults are about the rights and duties of children and young people. The above outlines a sociological framework of, on the one hand, the existing disadvantageous factors for children and young people and, on the other hand, the possible negative impact on these existing disadvantageous factors by COVID-19. It cannot be automatically inferred from the above reasoning that COVID-19 will lead to additional socioemotional and psychological damage in children and young people.

The premise of this article is that children and young people cannot be separated from their context. That context is the extended family, their peers, sisters and brothers, nieces and nephews, school, work, street, public transport and leisure. And also face-to-face, written and digital virtual communication. That is why I would like to call here for children and young people to be actively involved in the decision-making bodies in order to combat the adverse effects of COVID-19. After all, they are paying the price for the COVID-19 interventions of the generations above them.

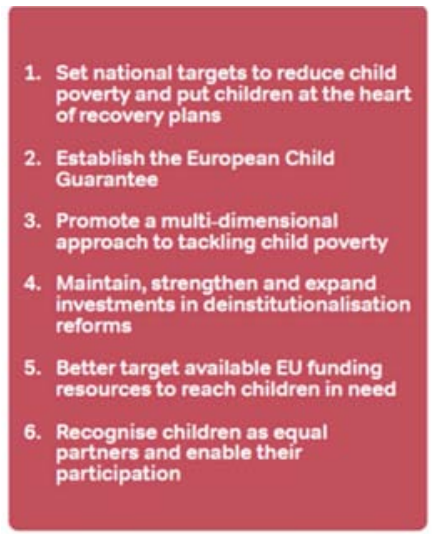

Figure 8. 'Growing up in lockdown: Europe's children in the age of COVID19. 2020 Eurochild Report. \#PuttingChildrenFirst' (page 4).

\subsection{Positive Psychology and a Conceptual Framework for Recovery of Children Affected by COVID-19 Through Their Extended Families}

Positive psychology focuses less on complaints, symptoms and disorders and the therapeutic treatments that flow from them. Positive psychology looks for ways to systemically address a pandemic, such as COVID-19. This section elaborates on a conceptual framework that focuses on families (western) and extended families (non-western). Positive psychology works with the following concepts: a) 'belonging', b) resilience, c) the strength resources of social systems, especially in (extended) families and neighborhoods, d) empathy and sympathy, and e) social safety. Some of these concepts from positive psychology are elaborated below for COVID-19 in children and adolescents.

"It is important to focus broadly on family members commonly serving as caregivers for children, including not only parents but also grandparents. Grandparents increasingly live in multigeneration households, and play an indispensable role as caregivers for grandchildren.

Furthermore, the percentage of children living in extended family homes that include their grandparents is $38 \%$ worldwide and nearly 50\% in the Asia-Pacific Region. 
Grandparents, who are often the most vulnerable to COVID-19, frequently provide psychosocial, practical, or financial support for their grandchildren [5]."

The extended family, especially among immigrants, contains many power tools and also possesses resilience [17]. Examples of power sources or tools are: a) believe that the (extended) family is successful, b) nurture hope, c) have a positive outlook on life, d) receiving support from family members, etc. An example of a possible COVID-19 power tool approach in an extended family is: 1) promote togetherness (by connecting), 2) supporting each other in daily matters (i.e. dividing tasks, educating, helping and transferring norms and values), 3) helping each other in crisis situations (i.e. working together, communicate and enforce house rules, solving daily conflicts as a result of COVID-19, and dealing with the pandemic), and 4) helping each other feel at home in the pandemic COVID-19 (i.e. involving others, actively learning to feel at home, and doing chores together with the extended family).

Extended families usually consist of 3-4 generations spread over several countries (mother and fatherlands). Extended families have a division of labor between them A well-known and traditional extended family model is the following. First of all, there are all the women of one and the same extended family, sometimes supplemented by their female neighbors, who are responsible for the upbringing of all the children, their husbands, the household chores and 'catching' conflicts (they are the ears and eyes of the extended family, as it were, and intervene to prevent conflicts). In the second, it is the men of the extended family who are responsible for finding and keeping jobs for all members of the extended family and therefore for the income of the extended family. In addition, they make sure that their own extended family in their community is looked upon with respect and trust. In short, a sophisticated social system that takes care of its members from conception to death. Thirdly, the extended family has peers who support each other. These are all the nieces and nephews. They are familiar to each other, they share the extended family's experiences, the worries of their caregivers and their own development. They support each other emotionally and as friends. I am not trying to idealize the extended family. Like any other social system in our society, extended families undergo changes, such as extended families turning into "blocks" of nuclear families, a complete transition to matriarchy, and disruptions and conflicts, the latter certainly due to the COVID-19 pandemic. In an extended family, priority number one is to resolve these disruptions, transitions and conflicts. Once that is resolved, the extended family can once again function as a protecting mantle ("envelope" in French) for its members (I borrowed this term from the work of Kitlyn Tjin A Djie ${ }^{13}$ ).

Resilience in extended families is defined below.

"Family resilience has been defined as the (extended) family's ability to "withstand and rebound from disruptive life challenges, strengthened and more resourceful" [23]. From decades of research and clinical experience, Dr.

13 https://www.vkjp.nl/tijdschrift-artikelen/tkjp-2013-4-beschermjassen-hetzelfoplossend-vermogen-van-families
Froma Walsh, one of the leading authorities on family resilience, has identified nine processes around the beliefs, organization, and communication of families that can shape their response to adversity [12].”

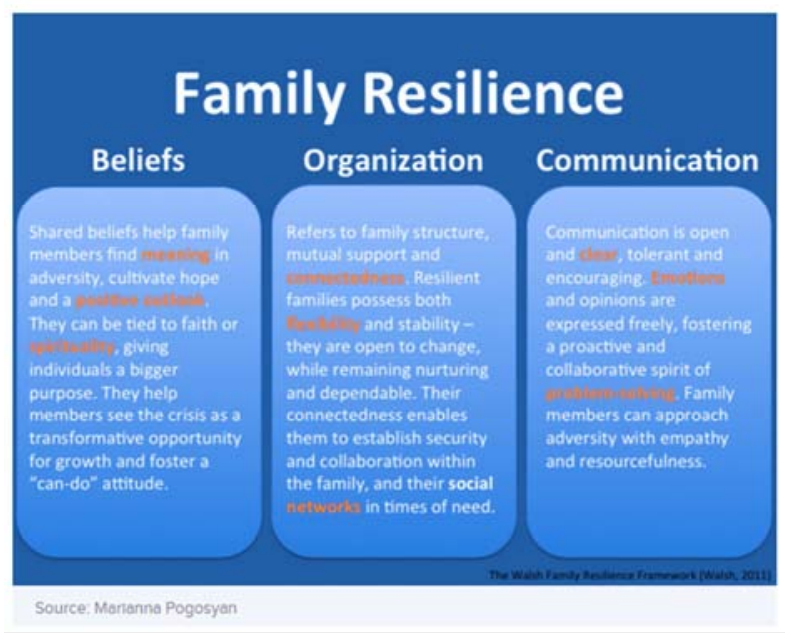

Figure 9. Family Resilience.

"Family resilience, as Dr. Walsh points out, is not just about weathering a storm. Rather, it's about turning adversity into a catalyst for the family's growth. It's about enriching relationships and making family members more skilled at coping with future stresses. We all strive for resilience. Who wouldn't want the ability to meet life's inevitable challenges with grace? But how are resources for resilience built within a unit of unique individuals, circumstances, and dynamics? With the magic of the small, everyday things, it appears. A conversation here, an activity there. Word by word, bond after bond, (extended) families fill their wells with strength and wisdom, hope and creativity. And the reassurance of this common well of reserves becomes a big part of their resilience."

Seamlessly, the following article ties in with the thinking developed by Pogosian [12] on the triggers of resilience in (extended) families. That article is by Prime [13] and is called 'Risk and Resilience in Family Well-Being During the COVID-19 Pandemic'. In their abstract, these authors say the following:

"The presented conceptual framework is based on systemic models of human development and family functioning and links social disruption due to COVID-19 to child adjustment through a cascading process involving caregiver well-being and family processes (i.e., organization, communication, and beliefs). An illustration of the centrality of family processes in buffering against risk in the context of COVID-19, as well as promoting resilience through shared family beliefs and close relationships, is provided."

Prime [13] launches a 'waterfall' model for addressing COVID-19 in extended families. While the name is understandable, I am not sure that the term 'waterfall' is a well-chosen metaphor. The explanation for the waterfall' model is possible: 'who sows the wind, will reap the 
whirlwind'. Why I am expressing this doubt is a legitimate question here. After studying the model (see also the following figure), I came to the following conclusions. Step 1 of the model presented by Prime [13] is that COVID-19 as a stressor is an unprecedented global assault on human existence. Following this constellation, their 'waterfall' model falls back on the balance between capabilities and workload in human social systems. In doing so, they lean heavily on resilience of the extended family. What does that mean? COVID-19 has made its impact felt at the macro, meso and micro levels. Marco are, for example, economic hardship (reduced or no more income), and social hardship (safety measures, such as 1.5 meters distance, allow very few visitors at home, even if they are family members, hand washing, mouth masks and ventilation). Meso are for example, disrupted systems at work, at home in the (extended) family, and in the neighborhood on the street. Systems that teach us how to cope with setbacks and that cushion us when setbacks occur. Micro is contamination and the death of caregivers and family members, which causes pillars of support for children and young people to disappear. Furthermore, the balance between carrying capacity and burden is like a rubber band. It can be pulled until it snaps. This is also how it works in social systems. In short, to continue the metaphor of the rubber band, it will become stronger if its elasticity increases. That is preventive extended family work, one might also say.

The model launched by Prime [13] is shown below. As mentioned earlier, this model leans heavily on that of Pogosian [12] and in particular on the (extended) family pillars which are put under considerable pressure by COVID19: "nine processes around the beliefs, organization (routines, rituals and rules), and communication of (extended) families that can shape their response to adversity."

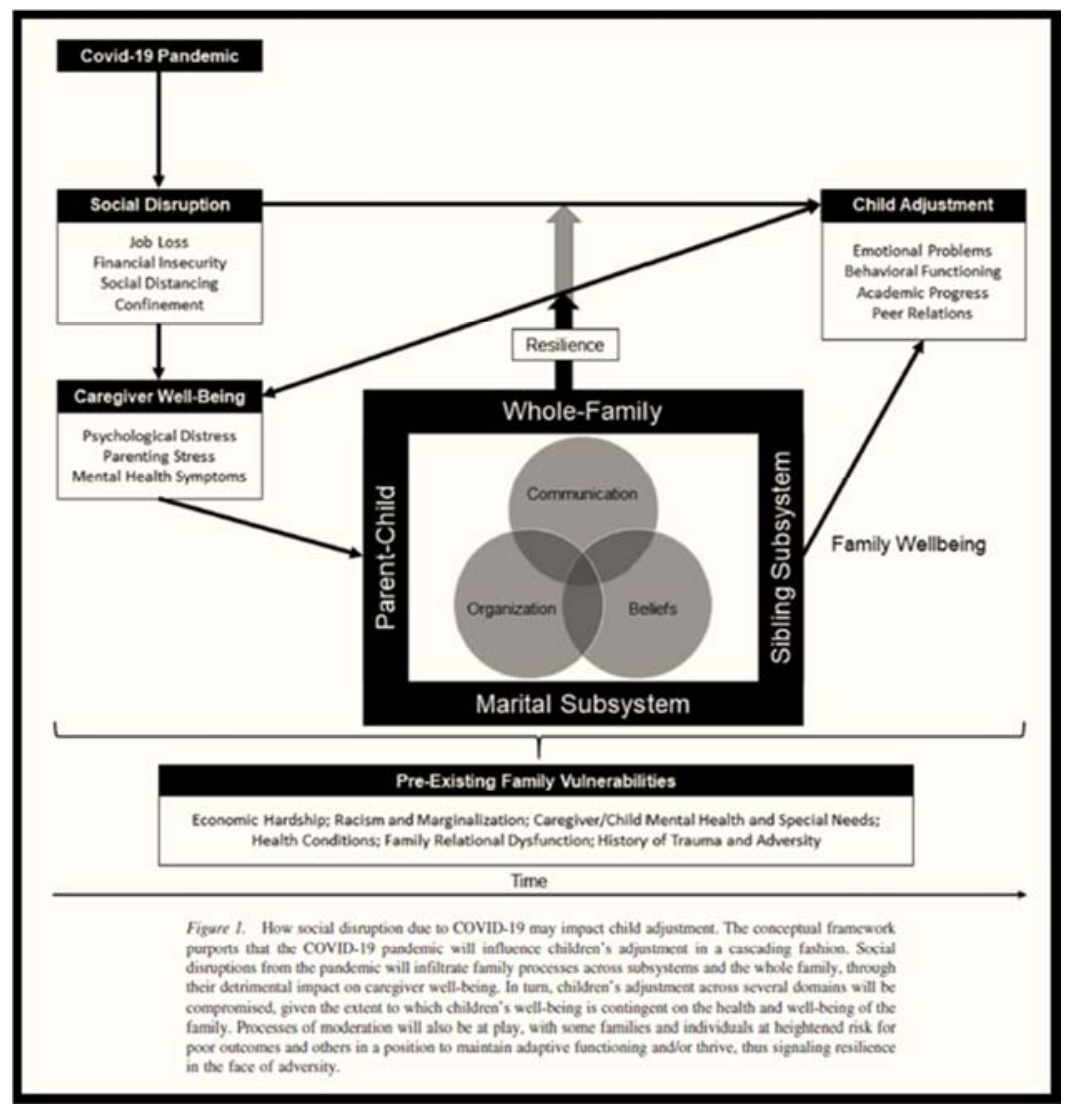

Figure 10. Extended Family Model and COVID-19.

Prime [13] drew the following conclusion from this excellent international overview.

"One goal of this article was to illuminate "how macrosocial changes may affect the smallest members of society, the children. There is ample cause for concern regarding the acute impact of COVID-19 on the wellbeing of the general population. The pandemic represents a global crisis not only of public health and economic stability but also of (extended) family well-being. As the leaders in the (extended) family, caregivers are put to task to generate hope; nourish relationships and emotional security; and negotiate (extended) family rules, rituals, and routines. At the same time, they are walking in unchartered territory-facing extraordinary levels of uncertainty, (extended) family upheaval, and fear."

A wonderful summary of concrete anti-COVID-19 measures for children, extended families, caregivers and the community that fits well with the above can be found in the following overview by Bartlett and Vivrette [1]. These antiCOVID-19 measures are divided into the following main categories:

"Protective factor \#1: Sensitive, responsive caregiving 
(including, spend quality time with children. Even short periods of time playing, reading, going outdoors, and talking can bolster children's sense of safety and security during uncertain or scary times), Protective factor \#2: Meeting basic needs (including, meeting the basic needs of children and families - such as food, shelter, clothing, and medical and mental health care - is essential to protecting children's well-being in stressful times. Actively mobilizing tangible resources for families during the pandemic is especially important for families experiencing additional risks, such as economic instability, job loss, and health or mental health needs), Protective factor \#3: Emotional support for children (including use the 3 R's (reassurance, routines, and regulation): Reassure children about their safety and the safety of loved ones; maintain predictable routines (e.g., sleeping, eating, learning, playing); support children's regulation skills by helping them manage difficult feelings (e.g., deep breathing, movement, quiet time); and make time for emotional "check-ins" (e.g., offer opportunities for children to ask questions, talk about their feelings, and get ageappropriate information and support), Protective factor \#4: Support for caregiver well-being (including, whenever possible, prioritize time and energy for activities that are most important and meaningful to caregivers and their families (e.g., enjoyable activities with family at home, celebrating birthdays and other important milestones, connecting with friends) and focus on what can be reasonably accomplished under the circumstances), and Protective factor \#5: Social connectedness (including, positive social connections are important protective factors for both children and adults during a pandemic. Although in-person contact may be limited, physical distancing should not turn into social isolation, which is a risk factor for child abuse and neglect, adult and youth substance use, and family violence. During disasters, children interact less frequently with mandated reporters and other adults who could recognize and report signs of trouble in a family. Monitoring children's safety is especially important during the pandemic."

\section{Conclusions}

Is the current generation of children and young people a lost generation because of COVID-19? That question is not easy to answer. Intuitively, the answer to this question can be said to differ from that of the doomsayers to that of the positivists. In psychology, or rather psychology/ psychiatry, a distinction is made between negative psychology (doommongers), that of symptoms and disorders, and positive psychology, that of systemic power sources and resilience to be used in the face of serious setbacks, such as the COVID19 pandemic. How does this article address the issue of 'Is the youth a lost generation by COVID-19'? This question is answered through two metaphors, the first of which is that of the lens, which represents what has gone wrong in our society, be it social, climatic or economic, and is reinforced and magnified by COVID-19. Secondly, that of the pressure cooker, as it were, compressing time and not allowing us humans the time to deal with the intersectional influences of the COVID-19 pandemic in time.

The lens as a metaphor for magnifying what was already going wrong in our society before COVID-19 provides the following insights. Among the victims of infection and death are people who have been vulnerable for some time. In the first place, these are elderly and middle-aged people with underlying medical physical problems, such as diabetes, high blood pressure and heart failure. For children, these elderly and middle-aged people are their grandmothers, grandfathers, aunts and uncles whom they could no longer visit overnight and walk hand in hand. This vulnerable group could arise because preventive medicine is not a priority, including exercising and eating healthily. Secondly, vulnerable people are immigrants and refugees who already suffer from insecure, very low incomes, living in small houses without facilities such as computers and Wi-Fi for their children. These vulnerable immigrants and refugees are the members of the extended family as caregivers of children and parents of children. The latter vulnerable group (refugees), but also the former (immigrants), has been created by neoliberal income policies that make the rich richer and the poor poorer, as well as by socio-economic institutional racism and exclusion in education, the labor market and health care. After all, neo-liberal politicians, adhere to the belief that human life can be regulated by business, whereas Karl Marx in 1867 in the book "Das Kapital. Kritiek der Politische Öekonomie" in 1867, Karl Marx already indicated that business is focused on profit maximization and does not care about the politics of income equality or, in other words, humanity.

The pressure cooker as a metaphor is used to clarify that the past, the COVID-19 present and future are compressed in time. In a short period of time, an intersectional approach has to be developed. Many governments with the exception of New Zealand with the female Prime Minister Jacinda Ardern do not have an intersectional COVID-19 approach. Most governments have a COVID-19 approach that focuses primarily on reducing infections and deaths. Hence, in this approach, protective measures especially lockdowns, hand washing, keeping a distance, as well as vaccines, have been given a key position to ensure that infections, hospitalizations and deaths from COVID-19 are as minimal as possible. The downside to this approach is that in the near future when COVID-19 is more under control, it becomes a case of mopping up, as non-medical life has received little or no attention. This challenge will now have to be met. It is hoped that the knowledge and skills of children and young people will be utilized. After all, they are the ones who pay for the damage. Making use of the knowledge and skills of children and young people means not only gathering knowledge from them, but also making them responsible for the future COVID-19 approach and asking them to help shape that future.

Before actually answering the question, "Is the current 
generation of children and young people a lost generation due to COVID-19?", intermediate steps are presented. First of all, 'facts' are presented on what impact COVID-19 has and has had on education. Various topics are discussed. During COVID-19, learning in the classroom, the lab, the lecture hall and work group rooms came to a complete standstill. In its place came online learning, which was technically only partially equipped for this mass use. Online learning requires building an infrastructure at home with parents and caregivers. The foundations of that infrastructure are parenting and house rules, social media rules, the new online 'learning staff', namely parents and caregivers, learning spaces in the home and the technical facilities such as Wi-Fi and computers for each of the children.

As far as I know, this social, human and technical organization for online learning did not come about with the support of the government, much depended on private and community initiative. It goes without saying that this massive change in the learning environment has leaned on what was already available. Supposedly present are parents and educators who can teach their children at home. This is the assumption that parents and educators can combine guiding children with their own work and allow children to get used to the "new" living environment, alone without peers at home. These are also home environments with sufficient computers and WIFI amplifiers. The availability of this online learning environment at home is unevenly distributed around the world. The richer the country, the richer the parents and caregivers, the more resources can be made available for this new online learning environment. This applies to home and educational institutions. Complications are illiteracy (almost four-fifth of a billion worldwide ${ }^{14}$ ), not speaking the language of the country of immigration $(48 \%$ of all 15 year old immigrants and refugees worldwide, OECD, [10] and lack of internet connections (in 2019, 54\% of the world's population has internet ${ }^{15}$, Europe $83 \%$ and Africa 28\%). Reassurances come from the Harvard OECD group that pupils and students in primary and secondary education are said to have fallen behind by two months, and from further research after the Christchurch earthquake that the learning deficit is not as bad as it seems, especially if teachers focus on what really needs to be learned at school. Personally, I am not inclined to take these relativizing remarks about the possible disadvantages of COVID-19 for children and young people for granted, especially against the background of the above complications alongside the permanent disruptions to the human environment worldwide caused by wars, famine and climate disasters.

Now that the context of COVID-19 acting as a magnifying glass and pressure cooker has been outlined, it is time to answer the question: what are the psychological consequences of COVID-19 for children and young people?

The answer is addressed in three ways. Firstly, through negative psychology; secondly, through a preventive

14 https://worldpopulationreview.com/country-rankings/literacy-rate-by-country 15 https://en.wikipedia.org/wiki/Global_Internet_usage approach that stems from negative psychology; and thirdly, through positive psychology.

Negative psychology looks at children and young people from a perspective that allows complaints, symptoms and disorders to be visualized and illuminated. Negative psychology, by the way, has a long tradition of working together with criminology. What is the reasoning of negative psychology? Because of COVID-19, the number of crimes involving children and young people has increased. Examples of such crimes are family violence (also against children and young people), marrying off young girls, sexual violence and assault. These experiences can be one-off or structural, i.e. frequent and regular over a long period of time. Due to these crimes and the medical approach of COVID-19, the core of which is total physical social isolation, children and young people develop complains and symptoms. These complaints are cast in the terminology of negative psychology. Examples from light to heavy are: lonely, skin craving, missing peers, not being able to see older people in the family, like grandma and grandpa, not being able to go out and chill with peers becoming depressed and anxious, and suffering more from psychiatric illnesses that were already there before COVID-19.

Paragraph 6.1 presents figures on direct and indirect victimization of children and adolescents due to COVID-19 and its mutants. This has been done for India, China and Africa as well as for Western countries. In addition, it is estimated how many inhabitants of our planet may have come into direct or indirect contact with COVID-19 healthcare providers. In total, this is about 2.2 billion people. That number includes their children, an estimated total of 560,000 . Children are sensitive to the fears and concerns of their caregivers in the extended family; the younger the more sensitive it seems.

It is noteworthy that China [7] gave high priority to coaching and counselling children and young people during the first outbreaks of COVID-19 and the associated lockdowns and quarantine. This concerned different groups of children. Children who were separated from their parents and caregivers because they were infected, children whose parents or caregivers had died, and children who had to stay at home because of quarantine. The Chinese Central Government -in particular the Ministry of Civil Affairs- has, to the best of its knowledge, facilitated the care of these children and young people. Examples of Chinese measures are nurses who were available $7 \times 24$ hours, many technical aids were used to ensure that children and young people remained in contact with caregivers and parents, and temporary mothers from the local community took on the care of these children and young people, all based on collectivist principles.

Paragraph 6.2 looks at preventive health care from the point of view of negative psychology. This perspective is also called psychoeducation. Through psycho-education on COVID-19, it can be explained that COVID-19 can lead to infection, illness and death of parents and educators and to isolation of children and young people due to quarantine and lockdown measures. Psychoeducation itself is curative because it makes one's own behavior and that of others 
predictable, making it easy to eradicate the nastiest aspects. A wonderful psychoeducational initiative of the European Union is 'My Hero is You'. This is a picture book and audio material made with and for children that educates them about COVID-19 and is available in 160 different languages.

Section 6.3 outlines the insights of positive psychology, which relies on the existing sources of strength and resilience of social groups of people who are actually connected to each other, such as extended families $(38 \%$ (50\% in Asia) of the world's population has its children raised by a member of the extended family), tribes and neighborhood residents. The assumption of positive psychology is that the consequences of COVID-19 for children and youngsters can only be combated by mobilizing or making use of these sources of strength and resilience of social groups of people who are connected with each other.

"Family resilience has been defined as the (extended) family's ability to "withstand and rebound from disruptive life challenges, strengthened and more resourceful" [23].

From decades of research and clinical experience, Dr. Froma Walsh, one of the leading authorities on family resilience, has identified nine processes around the beliefs, organization, and communication of families that can shape their response to adversity [12]."

What does this extended family approach mean in practice? Much experience has been gained with this approach in the Netherlands and France [17]. Here, too, it is true that issues and problems must first be identified, that sources of strength and resilience of the extended family are mapped out, and then a choice can be made from a large number of possible interventions. Possible options are the elimination of existing extended family conflicts, regular extended family consultations, having children and young people skype with the elderly in the family, having young people come together to explore how they can learn to live with the COVID-19 pandemic and finding out who from the extended family can guide young people and children with their schoolwork.

My overall conclusion is that the effects of COVID-19 on children and young people are profound and disruptive to their existing lifestyles. With an old-fashioned motto, we can claim that they are the generation of the future. This gives them the right to exert a real influence on the design of our society and society. They must not be treated as the new wage slaves of capitalism and neo-liberalism. This article zooms in on the socioemotional and psychological wellbeing of children and young people in this COVID-19 era that is far from over. This teaches us that the insights of the mental health services focused on complaints, symptoms and disorders are useful but that the mental health services are not equipped to serve such large numbers of children and young people also because child psychiatry and psychology are hardly committed to preventive work. Much larger numbers of children and adolescents can be reached with psychoeducation, as has been done with the children's book 'You are my Hero', made available in 160 languages by the European Union. The Chinese preventive approach should also be followed. Finally, positive psychology shows that health and the management of negative COVID-19 effects in children and adolescents can be promoted through the extended family approach.

\section{References}

[1] Bartlett, Jessica, Dym, and Vivrette, Rebecca (2020). Ways to Promote Children's Resilience to the COVID-19 Pandemic. Child Trends. https://www.childtrends.org/publications/waysto-promote-childrens-resilience-to-the-covid-19-pandemic.

[2] Chiarella, Sabrina, S, Poulin-Dubois, Diana (2015). "Aren't you supposed to be sad?" Infants do not treat a stoic person as an unreliable emoter. Infant Behavior and Development, Volume 38, February 2015, Pages 57-66. https://doi.org/10.1016/j.infbeh.2014.12.007.

https://www.sciencedirect.com/science/article/abs/pii/S016363 8314001210?via\%3Dihub.

[3] Cotte, June, Ratneshwar, S., and Mick, David, Clen (2004). The Times of Their Lives: Phenomenological and Metaphorical Characteristics of Consumer Time styles. 2004 by JOURNAL OF CONSUMER RESEARCH, Inc. Vol. 31 September 2004.

[4] Droeven, Valerie en Maenhout, Klaas (24 June, 2021). Ik heb dit jaar enkele leerlingen zien uitdoven, de lichtjes uit hun ogen verdwenen. De Standaard. https://ap.lc/QPnIk.

[5] Hillis, Susan D., Unwin, H., Juliette, T., Chen, Yu, Cluver, Lucie, Sherr, Lorraine, Goldman, Philip S., Ratmann, Oliver, Donnelly, Christl, A., Bhatt, Samir, Villveces, Andrés, Butchart, Alexander, Bachman, Gretchen, Rawlings, Laura, Green, Phil, Nelson III, Charles, A., and Flaxman, Seth. (2021). Global minimum estimates affected by COVID-19associated orphanhood and death of caregivers: a modelling study. THE LANCET. DOI: https://doi.org/10.1016/S01406736(21)01253-8.

https://www.thelancet.com/journals/lancet/article/PIIS01406736(21)01253-8/fulltext.

[6] Liang, Leilei, Rem, Hui, Cao, Ruilin, Hu, Yueyang, Qin, Zeying, Li, Chuanen and Mei, Songli (2020). The Effect of COVID-19 on Youth Mental Health. Psychiatric Quarterly (2020) 91: 841-852. https://doi.org/10.1007/s11126-02009744-3

[7] Liu, Jia, Jia, Bao, Yanping, Huang, Xiaolin, Shi, Jie and Lu, Lin (2020). Mental health considerations for children quarantined because of COVID-19. www.thelancet.com/childadolescent Vol 4 May 2020. Published Online March 27, 2020. https://doi.org/10.1016/S2352-4642(20)30096-1.

[8] Juneja, A., Singh, N., Sultan, A. and Juneja, A. (2020). Negative Impact of COVID-19 on the Lives of Children: an Indian Perspective. Journal of Advanced Scientific Research. J Adv Sci Res, 2020; 11 Suppl 3: 44-48.

[9] Mohapatra, Ranjan, K., Mishra, Snehasish, Azam, Mohammad, and Dhama, Kuldeep (2021). Letter to the Editor. COVID-19, WHO guidelines, pedagogy, and respite. Open Medicine 2021; 16: 491-493. https://doi.org/10.1515/med-2021-0266.

[10] OECD (2020). Tackling CORONAVIRUS (COVID-19): Contributing to a Global effort (oecd.org/coronavirus). What is the impact of the COVID-19 pandemic on Immigrants and their Children? 
[11] OECD (29 June, 2020). OECD Policy Responses to Coronavirus (COVID-19). Education and COVID-19: Focusing on the long-term impact of school closures. https://www.oecd.org/coronavirus/policy-responses/educationand-covid-19-focusing-on-the-long-term-impact-of-schoolclosures-2cea926e/.

[12] Pogosyan, Marianne (2017). Resilience. What Makes Families Resilient? Nurturing strength amid adversity. Psychology Today. Posted Oktober 11, 2017 https://www.psychologytoday.com/us/blog/betweencultures/201710/what-makes-families-resilient.

[13] Prime, Heather, Browne, Dillon T. and Wade, Mark (2020). Risk and Resilience in Family Well-Being During the COVID-19 Pandemic. American Psychologist. 2020, Vol. 75, No. 5, 631-643. ISSN: 0003-066X http://dx.doi.org/10.1037/amp0000660.

[14] Rielaender, Jan (2020). COVID-19 impacts through the lens of exposure and Resilience. Development Co-operation Report 2020: Learning from Crises, Building Resilience. https://www.oecd-ilibrary.org/sites/8faa5454en/index.html?itemId=/content/component/8faa5454-en.

[15] Rousseau, Cécile, and Miconi, Diana (2020). Protecting Youth Mental Health During the COVID-19 Pandemic: A Challenging Engagement and Learning Process. Journal of the American Academy of Child \& Adolescent Psychiatry. Volume 59 / Number 11 / November 2020. https://doi.org/10.1016/j.jaac.2020.08.007.

[16] Schneble, Marc, Nicola, De, Giacomo, Kauermann, Göran and Berger, Ursula (2020). Spotlight on the dark figure: Exhibiting dynamics in the case detection ratio of COVID-19 infections in Germany. MedRxiv preprint doi: https://doi.org/10.1101/2020.12.23.20248763; this version posted December 24, 2020.

[17] Steinmetz, Carl H. D. \& Berg, van den, Jette C. (2015). De Grootfamilie aan Zet. De participatiemaatschappij in het klein. Mens en Maatschappij. ISBN: 978-94-92182-1. Grootfamilieaanzet.

https://www.researchgate.net/publication/322342263_De_Gro otfamilie aan_Zet_De participatiemaatschappij_in het klein.
[18] Steinmetz, Carl H. D. (2020). COVID-19, Superdiversity, Crisis-Communication and Leadership: Lessons to be Learned International Journal of Economics, Business and Management Research Vol. 4, No. 06; 2020. https://www.researchgate.net/publication/342420443 COVID -19 SUPERDIVERSITY CRISISCOMMUNICATION_AND_LEADERSHIP_LESSONS_TO BE_LEARNED.

[19] Steinmetz, Carl Hermann Dino (2021). Somatic and Psychological Consequences of Covid-19 on Healthcare Professionals and its Effects on Healthcare Delivery in a Teaching Hospital in Khyber Pakhtunkhwa, Pakistan. International Journal of Medical Science and Health Research. $\begin{array}{lllll}\text { Vo. } & 5 . & \text { No. } & 021 \text {; }\end{array}$ https://www.researchgate.net/publication/349057534_Somatic and Psychological Consequences of Covid-

19_on_Healthcare_Professionals_and_Its_Effects_on_Healthc are Delivery in a Teaching Hospital in Khyber Pakhtunkh wa_Pakistan.

[20] Steinmetz, Carl H. D. (2021). Coping with Incidents: a First Step Towards Overhaul. International Journal of Medical Science and Health Research. Vol. 5. No. 02: 2021. DOI: 10.51505/ijmshr.2021.5207.

https://www.researchgate.net/publication/350063392_Coping with_Incidents_a_First_Step_Towards_a_Thorough_Overhaul.

[21] Thomson, Helen (2021). Children with long covid. 10 | New Scientist | 27 February 2021. doi: 10.1016/S02624079(21)00303-1.

https://www.ncbi.nlm.nih.gov/pmc/articles/PMC7927578/.

[22] Tso, W. W. Y., Wong, R. S., Tung, K. T. S. et al. Vulnerability and resilience in children during the COVID-19 pandemic. Eur Child Adolesc Psychiatry (2020). https://doi.org/10.1007/s00787-020-01680-8.

[23] Walsh, F. (2011). Family resilience: A collaborative approach in response to stressful life events. In S. M. Southwick, D. Charney, M. J. Friedman (Eds.). Resilience and mental health: Challenges across the lifespan (pp. 149-161). Cambridge: Cambridge University Press. 